\title{
Study of the Anti-Inflammatory and Healing Properties of the Rhizomes of Carthamus Caeruleus L. (Asteraceae) Harvested in the Region of Tipaza
}

\author{
Type of article: Conference abstract \\ Nabahat. Benmansour1, R. Mohamed Said1, Fella El Hanbali 2, Hamida Cherif1, Mohamed \\ Akssira2 \\ 1 Department of Biology, Faculty of SNV, Blida, Algeria \\ 2Faculté des Sciences et Techniques, Mohammedia, Maroc \\ Corresponding Author: nabahats@yahoo.fr
}

\begin{abstract}
:
Background: In some regions of Algeria, in Tipaza, natural medicine still occupies a place of choice in the treatment of many pathologies. Among these natural remedies are extracts of the rhizomes of Carthamus caeruleus L are used to treat burns with its astringent properties. Medicinal plant extracts contain a variety of phenolic compounds that are attributed to various biological activities (antioxidant and antimicrobial activity).

Methods: Our present study was conducted on the roots of Carthamus caeruleus $L$. harvested in the Tipaza region during the spring season. In order to promote this plant, we evaluated the anti-inflammatory activity and healing activity of the aqueous extract of the powder of the roots of Carthamus caereulus L., studying the anti-inflammatory effect by measuring the volume of the edema of the paw that has received carrageenan $1 \%$. Circular incision of $2 \mathrm{~cm}$ in diameter was made in Wistar rats to evaluate the healing activity of the aqueous pasty extract of the rhizomes of Carthamus caeruleus $L$ at $100 \mathrm{mg} / \mathrm{kg}$.

Results: They show that aqueous extracts of Carthamus caeruleus $L$ rhizomes at the dose of $100 \mathrm{mg} / \mathrm{kg}$ are opposed to the increased edema induced by the carrageenan $1 \%$ in rats with a percentage of inhibition of edema volume of $87.34 \%$ at the 6th hour. Concerning the healing activity, the results show that the application of the aqueous extracts of the roots of Carthamus caereulus L.at dose of $100 \mathrm{mg} / \mathrm{kg}$ on the wounds causes their healing at the end of 14 days.
\end{abstract}

Conclusion: Aqueous extracts of the roots of Carthamus caereulus L. show healing properties and anti-inflammatory effects. These results could justify the use of this plant in traditional medicine against inflammatory diseases.

Keywords: Carthamus Caeruleus L. Rhizome Powder, Anti-Inflammatory Activity, Healing Activity.

\section{Conflict of interest statement}

This article is a conference abstract presented at the International Congress on Health Sciences and Medical Technologies, Tlemcen Algeria 5-7 December 2019, ICHSMT' 19. 


\section{Authors' biography}

No Biography.

\section{References}

[1] Hamadi F., Boudif K., Djouab A., Allane T., Benmounah A. and Benamara S. (2014). Clinical phytotherapy: Characterization of a traditional semi-solid anti-burn preparation. Phytotherapy, France: 1-7.

[2] Ghazghazi.H., Chedia A., Abdererazak M. and Brahim H. (2013). Comparison of polyphenol content and antioxidant activity of methanoid extracts from the four plants collected from northern Tunisia. Microbial.Hyg.Alim.73 (25): 37-41. 